\title{
Corrigendum: Visual Depictions of Our Evolutionary Past: A Broad Case Study Concerning the Need for Quantitative Methods of Soft Tissue Reconstruction and Art-Science Collaborations
}

\author{
Ryan M. Campbell ${ }^{1 * t}$, Gabriel Vinas ${ }^{2 t}$, Maciej Henneberg ${ }^{1,3 t}$ and Rui Diogo ${ }^{4 t}$ \\ ${ }^{1}$ Department of Anatomy \& Pathology, University of Adelaide, Adelaide, SA, Australia, ${ }^{2}$ Department of Sculpture, Arizona \\ State University, Tempe, AZ, United States, ${ }^{3}$ Institute of Evolutionary Medicine, University of Zurich, Zurich, Switzerland, \\ ${ }^{4}$ Department of Anatomy, Howard University, Washington, DC, United States
}

OPEN ACCESS

Edited and reviewed by:

Stefano Dominici,

University of Florence, Italy

${ }^{*}$ Correspondence:

Ryan M. Campbell

ryan.campbel/@adelaide.edu.au

TORCID:

Ryan M. Campbell orcid.org/0000-0003-2630-1701

Gabriel Vinas orcid.org/0000-0003-3374-3460

Maciej Henneberg orcid.org/0000-0003-1941-2286

Rui Diogo

orcid.org/0000-0002-9008-1910

Specialty section:

This article was submitted to Paleontology,

a section of the journal

Frontiers in Ecology and Evolution

Received: 02 June 2021 Accepted: 16 June 2021 Published: 08 July 2021

Citation:

Campbell RM, Vinas G, Henneberg M and Diogo R (2021) Corrigendum: Visual Depictions of Our Evolutionary Past: A Broad Case Study Concerning the Need for Quantitative Methods of Soft Tissue Reconstruction and

Art-Science Collaborations.

Front. Ecol. Evol. 9:719193. doi: 10.3389/fevo.2021.719193
Keywords: artistic license, facial approximation, hominid, hominin, hard tissue, soft tissue

\section{A Corrigendum on}

Visual Depictions of Our Evolutionary Past: A Broad Case Study Concerning the Need for Quantitative Methods of Soft Tissue Reconstruction and Art-Science Collaborations

by Campbell, R. M., Vinas, G., Henneberg, M., and Diogo, R. (2021). Front. Ecol. Evol. 9:639048. doi: $10.3389 /$ fevo.2021.639048

In the original article, there were the following errors:

There was an error in the word "genetic tool," which should have been written as "genetic tools."

A correction has been made to the first sentence in the section titled INTRODUCTION: WHY STUDY AND RECONSTRUCT MUSCLES on Line 30 of the corrected manuscript:

At a time in which we are increasingly exposed to acclaims about new powerful genetic tools in the media and academia, one may wonder as to why we would focus on muscle reconstructions at all in this introductory paper of this special issue.

There was an error in the naming of a Figure. We wrote Figure 3 when we meant to say Figure 2.

A correction has been made to the first sentence in the section titled Methods and Techniques Used for Reconstructing Hominids, Reconstructing Soft Tissues, paragraph 6 on Line 490 of the corrected manuscript:

In an effort to move away from intuition, our second facial reconstruction of Lucy (Figure 4) used equations derived from regression analyses of anatomically modern humans (Simpson and Henneberg, 2002). As one can see, it differs in appearance from the earlier reconstruction of Lucy in Figure 2, which was done intuitively without empirical data.

There was an error in the figure caption for Figure 3 . We wrote " 1 year" when we should have written one year.

A correction has been made to figure caption 3 in the section titled Figure captions on Line 1110 of the corrected manuscript:

Figure 3. Two facial reconstructions of the Taung child (without hair and pigment) that were produced one year apart. Please note how variability between these reconstructions is exemplified by the subjective decision to depict the subject as more apelike (A) or more humanlike (B). 
There was an error repeating the same word twice. For ease of reading, this word should be removed.

A correction has been made to the last sentence in the first paragraph in the section titled A Brief History of Hominin Facial Reconstruction on Line 140 of the corrected manuscript:

We would like to be transparent with the reader and admit that this section is by no means a complete list of all the reconstructions that have ever been produced, however, it does include the most well-recognized practitioners and reconstructions that were featured in scholarly publications, scientific textbooks, and on display at institutions of international repute.

An in-text citation for Weidernreich and Swan was incorrectly formatted throughout a paragraph in the manuscript.

A correction has been made to in-text citation in the section titled Methods and Techniques Used for Reconstructing Hominids, Reconstructing Hard Tissues, paragraph 2 of the corrected manuscript:

Methods for the reconstruction of hominin crania have been, and are still being, developed (Kimbel et al., 1984; Kimbel and White, 1988; Zollikofer et al., 2005; Gunz et al., 2009; Suwa et al., 2009; Kimbel and Rak, 2010; Benazzi et al., 2011; Amano et al., 2015; Brassey et al., 2018). In 1984, Kimbel, White, and Johanson reconstructed a male Australopithecus afarensis skull. The skull was a composite reconstruction that incorporated the skeletal elements from 12 different supposedly male fossil specimens found from sediments at A.L. 200-1a and one specimen found at A.L. 333/333w. This skull was later revised after the discovery of further fossil evidence (Kimbel and White, 1988). Similarly, in 1996, Tattersal and Sawyer revised Weidernreich and Swan's 1937 reconstruction of the skull of Homo erectus from a collection of casts from Zhoukoudian, China (Tattersall and Sawyer, 1996). This reconstruction was different from the Weidenreich and Swann skull, which was reconstructed as a female, whereas Tattersal and Sawyer reconstructed the skull as a male (Tattersall and Sawyer, 1996). To the knowledge of the authors, these are two of the only physical reconstructions of hominin skulls that have had their initial reconstruction and subsequent revision formally published. What this means for all other reconstructions of hominin skulls is unclear.

There was an error in the description of Figure 7 in the main text. We wrote "the Taung child (A) and Lucy (B)," but we meant to say "Lucy (A) and the Taung child (B)."

A correction has been made to the sentence in the section titled Methods and Techniques Used for Reconstructing Hominids, Reconstructing Soft Tissues, paragraph 9 on Line 547 of the corrected manuscript:

As can be seen in the completed facial reconstructions of Lucy (A) and the Taung child (B) presented in Figure 7, their skin tones differ significantly.

The order of names in a figure were written back to front. It was written as "the Taung child and Lucy," but it should have been written as "Lucy and the Taung child."

A correction has been made to the sentence in the section titled Methods and Techniques Used for Reconstructing
Hominids, Reconstructing Soft Tissues, paragraph 10 on Line 574 of the corrected manuscript:

For our reconstruction of Lucy and the Taung child presented in Figure 7, each hair was individually implanted into silicone casts of the reconstructions using a crown punching needle following the direction of hair in Homo sapiens and great apes described in Kidd (1903).

There is a spelling error in the keywords of the original article. A word is written in Australian English as "License" but should have been written as "license" in American English.

A correction has been made to the Keywords on Line 27 of the corrected manuscript:

keywords: artistic license, facial approximation, hominid, hominin, hard tissue, soft tissue

There is an error in the order of words that impedes legibility in the middle of a sentence. The sentence initially read as "but also to learn," but should be "but to also learn."

A correction has been made to the sentence in the section titled Introduction: Why Study and Reconstruct Muscles? Third paragraph, line 77 of the corrected manuscript:

This therefore illustrates how crucial it is to undertake accurate muscle reconstructions of fossils, to not only understand their functional morphology, and biology as a whole-bones do not move without muscles-but to also learn more about their evolutionary relationships, history, and adaptations.

A word was missing. The word missing was "of," which should have come before the words "years ago." It should be "of years ago."

A correction has been made to the sentence in the section titled Introduction: Why Study and Reconstruct Muscles? Fourth paragraph, line $\mathbf{9 4}$ of the corrected manuscript:

Over the last century, there has been a huge interest in reconstructing the face of members of our human lineage that lived many thousands, or even some millions, of years ago.

There was an error of unnecessary words that calls for their removal. "the entire" should be removed so the sentence just reads “...underlying evolutionary science."

A correction has been made to the sentence in the section titled Introduction: Why Study and Reconstruct Muscles? Fourth paragraph, line 106 of the corrected manuscript:

It is based on Charles Lyell's uniformitarian principle underlying evolutionary science.

There is an error in the use of past tense. We used "were" when it should have been "are."

A correction has been made to the sentence in the section titled A Brief History of Hominin Facial Reconstruction: First paragraph, line 142 of the corrected manuscript:

We would like to be transparent with the reader and admit that this section is by no means a complete list of all the reconstructions that have ever been produced, however, it does include the most well-recognized practitioners and reconstructions that are featured in scholarly publications, scientific textbooks, and on display at institutions of international repute.

There was an error with the use of a comma, where a transition would have sufficed. 
A correction has been made to the sentence in the section titled A Brief History of Hominin Facial Reconstruction: third paragraph, line 162 of the corrected manuscript:

Is it important to note here that not all reconstructions of hominins have been produced in $3 \mathrm{D}$ since $2 \mathrm{D}$ reconstructions are arguably more numerous and thus any review would be incomplete without acknowledging them.

There was an error in the use of the singular "tissue." It should be a plural and written as "tissues."

A correction has been made to the sentence in the section titled Reconstructing Hard Tissues: First paragraph, line 251 of the corrected manuscript:

Therefore, before the soft tissues for any hominin can be considered, the osteological material must first be reconstructed.

There is an unnecessary use of descriptive words "better preserved." For ease of reading these words "better preserved" should be removed.

A correction has been made to the sentence in the section titled Reconstructing Hard Tissues: Fifth paragraph, line 315 of the corrected manuscript:

Since Lucy was discovered, other skulls have been found.

There is a missing plural " $s$ " after the word "reconstruction." It should read "reconstructions"

A correction has been made to the sentence in the section titled Reconstructing Soft Tissues: Fourth paragraph, line 459 of the corrected manuscript:

Given that the soft tissues are tailored to each skull and are based on the verified relationships between soft tissue and craniometric dimensions, this method ought to be explored further, especially in great ape material, for the possibility of producing a set of regression models that have inter-species compatibility could reduce most of the variability between facial reconstructions of the same individual.

There is an unnecessary "the" in a sentence and it should be removed.

A correction has been made to the sentence in the section titled Reconstructing Soft Tissues: Fifth paragraph, line 477 of the corrected manuscript of the corrected manuscript:

Much like soft tissue thickness, these features have been either reconstructed intuitively or using methods derived from studies of anatomically modern humans and great apes.

There is a missing comma after the word "evidence."

A correction has been made to the sentence in the section titled The Ethics of Reconstruction and Societal Implications Fourth paragraph, line 694 of the corrected manuscript:

\section{REFERENCES}

Amano, H., Kikuchi, T., Morita, Y., Kondo, O., Suzuki, H., Ponce, et al. (2015). Virtual reconstruction of the Neanderthal Amud 1 cranium. Am. J. Phys. Anthropol. 158, 185-197. doi: 10.1002/ajpa.22777

Benazzi, S., Bookstein, F. L., Strait, D. S., and Weber, G. W. (2011). A new OH5 reconstruction with an assessment of its uncertainty. J. Hum. Evol. 61, 75-88. doi: 10.1016/j.jhevol.2011.02.005

Brassey, C. A., O’Mahoney, T. G., Chamberlain, A. T., and Sellers, W. I. (2018). A volumetric technique for fossil body mass estimation
However, when artists operating as disseminators of science fail to make sure their models showcase the best available evidence, they fall short in their role of not just educators but artists as well.

There is a grammar issue with the word "ones." It should have been written as "one's."

A correction has been made to the sentence in the section titled The Ethics of Reconstruction and Societal Implications Fifth paragraph, line 730 of the corrected manuscript:

It may not sound like a point of scientific relevance, but in the field of visual arts one's audience, content, and context are inextricably linked.

There is a misuse of the prefix "un." It needs to be moved from "scientifically" to the word "substantiated" to read "scientifically unsubstantiated."

A correction has been made to the sentence in the section titled The Ethics of Reconstruction and Societal Implications, Fifth paragraph, line 736 of the corrected manuscript:

Consider how young, would-be academics of minority groups feel as they are readily encountered by not just scientifically unsubstantiated material, but material that echoes a history of racist attitudes toward groups that look like them.

There is a missing comma after "Yet" at the start of a sentence.

A correction has been made to the sentence in the section titled The Ethics of Reconstruction and Societal Implications, Fifth paragraph, line 760:

Yet, there may not be a need to draw such a dichotomous view; if the statue served as an entrance piece that primes the viewers to think about how much we do not yet know, and how heavily veiled the truths about our past are, it can begin a healthy dialogue about what the rest of this imagined exhibit may present to its visitors in the way of fossils and other remains.

There is a spelling error of the word "analyzed." It Is currently in Australian English as "analysed" but should be changed to US spelling.

A correction has been made to the sentence in the section titled Author Contributions, line 853:

RC initiated the investigation into scientifically accurate hominin reconstructions, analyzed the literature, wrote the majority of the manuscript, and edited the whole version of the manuscript.

The authors apologize for these errors above and state that they do not change the scientific conclusions of the article in any way. The original article has been updated.

applied to Australopithecus afarensis. J. Hum. Evol. 115, 47-64 doi: 10.1016/j.jhevol.2017.07.014

Gunz, P., Mitteroecker, P., Neubauer, S., Weber, G. W., and Bookstein, F. L. (2009). Principles for the virtual reconstruction of hominin crania. J. Hum. Evol. 57, 48-62. doi: 10.1016/j.jhevol.2009.04.004

Kidd, W. (1903). The Direction of Hair in Animals and Man. London: Ballantyne, Hanson \& Co.

Kimbel, W. H., and Rak, Y. (2010). The cranial base of Australopithecus afarensis: new insights from the female skull. Philos. Trans. R. Soc. Lond. Biol. Sci. 365, 3365-3376. doi: 10.1098/rstb.2010.0070 
Kimbel, W. H., and White, T. D. (1988). A revised reconstruction of the adult skull of Australopithecus afarensis. J. Hum. Evol. 17, 545-550. doi: 10.1016/0047-2484(88)90042-5

Kimbel, W. H., White, T. D., and Johanson, D. C. (1984). Cranial morphology of Australopithecus afarensis: a comparative study based on a composite reconstruction of the adult skull. Am. J. Phys. Anthropol. 64, 337-388. doi: 10.1002/ajpa.1330640403

Simpson, E., and Henneberg, M. (2002). Variation in soft-tissue thicknesses on the human face and their relation to craniometric dimensions. Am. J. Phys. Anthropol. 118, 121-133. doi: 10.1002/ajpa. 10073

Suwa, G., Asfaw, B., Kono, R. T., Kubo, D., Lovejoy, C. O., and White, T. D. (2009). The Ardipithecus ramidus skull and its implications for hominid origins. Science 326:68. doi: 10.1126/science. 1175825
Tattersall, I., and Sawyer, G. J. (1996). The skull of "Sinanthropus" from Zhoukoudian, China: a new reconstruction. J. Hum. Evol. 31, 311-314. doi: 10.1006/jhev.1996.0063

Zollikofer, C. P. E., Ponce, de León, M. S., Lieberman, D. E., Guy, F., Pilbeam, D., et al. (2005). Virtual cranial reconstruction of Sahelanthropus tchadensis. Nature 434, 755-759. doi: 10.1038/nature03397

Copyright (c) 2021 Campbell, Vinas, Henneberg and Diogo. This is an open-access article distributed under the terms of the Creative Commons Attribution License (CC $B Y)$. The use, distribution or reproduction in other forums is permitted, provided the original author(s) and the copyright owner(s) are credited and that the original publication in this journal is cited, in accordance with accepted academic practice. No use, distribution or reproduction is permitted which does not comply with these terms. 